\title{
Jacket for Upper Body Immobility using a Wrapping Process
}

\author{
Kate Annett-Hitchcock, North Carolina State University, USA
}

Keywords (Jacket; Immobility; Universal Design; Patent)

Contextual review and concept statement Lack of upper body mobility is experienced by many people on a daily basis, and can be a temporary or permanent state. People who cannot lift or turn their torso, shoulders and arms have a range of difficulties in donning, doffing and securing clothing. The severity of the disability can create difficulties even with the use of assistive devices. These difficulties can extend to caretakers who assist in these processes (Nevala et al., 2003). Previous research has investigated accessibility through external means, such as assisting the dressing process using robots (Kapusta et al, 2019; Mitzner et al., 2013; Yamazaki et al, 2016) but these solutions have limited success when there is no voluntary body mobility. Design scholars have explored creating garments that support the upper body (McRoberts et al, 2015) but these test garments have to be donned over the head, requiring arms to be lifted. When there is acute and/or chronic pain in the shoulder, upper arm, upper back and neck area, the lifting of the arm to gain access to a sleeve can create more pain and potentially further injury. In carrying out research for a book, I came across an entry in Textile World Record (1914) which described a design for "An Improved Undershirt", for which a patent had recently been issued. This design was created with the objective of providing a garment "for children or invalids... without fixed fastening... so that there are no hard or cumbersome buttons and materials ... providing an easily adjustable garment which may be fastened with proper safety devices passed through the fabric" (p.145). The description of the garment, along with the accompanying illustration, appeared to me as an early example of universal design (Story et al., 1998), because of its applicability to multiple populations with a variety of physical challenges. I was also struck by the novelty of the design, shown by a sketch (Figure 1) and the final paragraph of the description; "It will thus be readily seen that the garment, when it is in unfolded position, can be laid out flat on any desired surface and the infant or invalid upon whom it is desired to be placed may be laid upon this back portion, and the flaps and bands carried around the portions that they are designed to cover without unnecessary rolling or disturbance of the wearer" (p. 146). It was this description of the wrapping of the body that inspired me to investigate adaptation of the design for adults with upper body immobility.

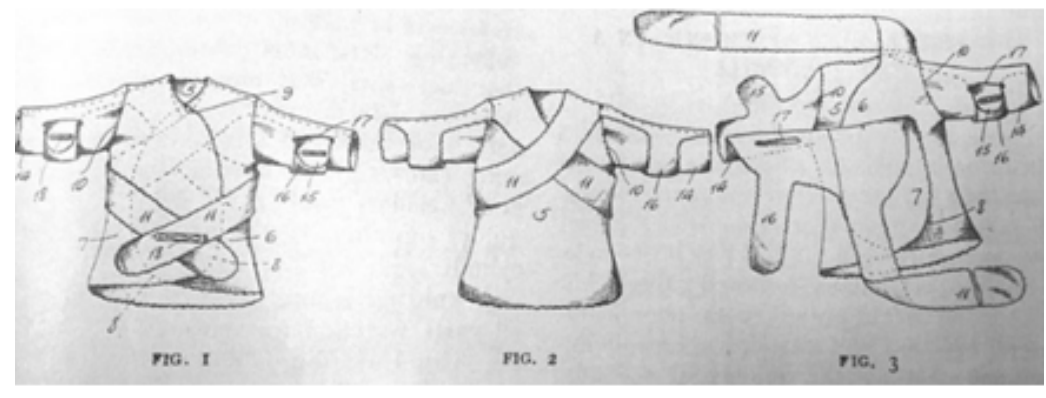

Figure 1. Patent sketch of An Improved Undershirt, as depicted in Textile World Record (1914), page 145.
Aesthetic properties and visual impact It was important that the finished garment look as close to a jacket as possible once it was on the body. For this reason I decided to remove the straps which wrapped around the body in the original design (see Figure 1), and allow the garment to swing free at the front. I

Page 1 of 3

(c) 2020 The author(s). Published under a Creative Commons Attribution License (https://creativecommons.org/licenses/by/4.0/), which permits unrestricted use, distribution, and reproduction in any medium, provided the original work is properly cited.

ITAA Proceedings, \#77 - https: //itaaonline.org 
used a sea-green/teal thin wale corduroy with a contrasting plaid woven facing for visual interest. The plaid was also used to make a tie on the wearer's right front, which allows for adjustment and at the same time asymmetric visual interest. I color-coded the snaps at the shoulders and the sleeve so that the design is easily understood by the dresser. I used Red for Right side and Lavender for Left side. As another point of visual interest, I quilted the sleeve tabs, which in addition to providing contrast to the lines of the corduroy, strengthened and stiffened the tabs for easier insertion through the oversized bound buttonholes. Even though the principles of Universal Design do not include aesthetic properties, I believe that a marketable product must have aesthetic appeal and thus aesthetic value is understood in Principle \#1, Equitable Use, defined as "The design is useful and marketable to people with diverse abilities" (Story et al., 1998).

Process, technique, and execution An historical patent was discovered which informed my design process, as well as inspiring the initial idea. Parsons (2015) makes the case for the use of historic patents and discusses gaining and sharing insight through the study of past techniques and replication of patterns. As a researcher I agree that the discovery of previously undeveloped ideas brings them to a new audience, providing value to wearers and informing new ways of creating. Initially, I analyzed the illustrations and developed paper patterns in half-scale, which I taped onto a half-scale form to ensure correct design engineering. Once the shapes and interlocking pieces were corrected, I doubled the size of the pattern to test a stitched muslin on a full-scale form. I proceeded through three iterations of prototype, making adjustments to the shapes due to the changes in proportion, and editing along the way, with feedback from a nurse who has experience with potential customers. Several challenges presented themselves, for example, deciding on the fastenings. The original directions mentioned only that the sleeve flaps were "secured by pins", and that "proper fastening devices passed through the two thicknesses of fabric" (p. 146). As described above, I decided upon color-coded snaps for sleeve and shoulders; a velcro fastening on the inside of the wrap front, and ties for the outside. Facings and interior panels were finished with a three-thread overlock, and the garment was stitched together with a 301 lockstitch. All edges are faced except the hem, which was handstitched.

Cohesion Visually, the asymmetric wrap front and sleeve details form a cohesive and complex unified look to the garment, which does not allude to its innate functional purpose.

Complementary colors have been selected to blend and unify, and topstitching used sparingly on the sleeves to provide border definition.

Significance, rationale, and contribution The purpose of this creative work was to design and make a garment for a person who lacks mobility in their upper body, by taking away the necessity of lifting the arms to put them into traditional sleeves. Instead of the body having to be maneuvered into the garment, the garment is wrapped around the person. In addition, the design process was guided by the principles of universal design throughout, as suggested by Park et al. (2014). The contribution of this design to the field is to show that normative processes for upperbody garment development can be challenged to provide

Page 2 of 3

(c) 2020 The author(s). Published under a Creative Commons Attribution License (https://creativecommons.org/licenses/by/4.0/), which permits unrestricted use, distribution, and reproduction in any medium, provided the original work is properly cited.

ITAA Proceedings, \#77 - https://itaaonline.org 
improved functionality and maintain aesthetic qualities for the wearer. In addition, it shows that by looking at historical work, especially when documented in the form of a patent, there is still much to be learned and developed for the good of society.

Originality and innovation This lies with the original writer of the patent, whose idea it was to devise a method of wrapping a supine body, such as an infant, with a garment, instead of trying to force arms into sleeves. Even though, according to patent rules established by the US Congress in 1861, which would have governed this undershirt patent, the copyright would have expired 17 years after filing (USPTO, 2018), I feel that the design warranted further development and exploration for use with people who have difficulty moving their arms to put them into sleeves. I feel that I have contributed innovation by realizing the final three-dimensional garment into a marketable format, and adding aesthetic features, thereby providing a universally-designed garment which can also be worn as a jacket by those without upper body mobility challenges.

\section{References}

Kapusta, A., Erickson, Z., \& Clever, H.M. (2019). Personalized collaborative plans for robotassisted dressing via optimization and simulation. Autonomous Robots, 43, 2183-2207.

McRoberts, L.B., Black, C.M., \& Cloud, R.M. (2015). Evaluation of a prototype soft-structured thoracic posture support garment. Clothing and Textiles Research Journal, 34(2), 143-158.

Mitzner, T.L., Chen, T.L., \& Kemp, C.C. (2014). Identifying the potential for robotics to assist older adults in different living environments. International Journal of Social Robotics, 6, 213227.

Nevala, N., Holopainen, J., Kinnunen, O. \& Hanninen, O. (2003). Reducing the physical work load and strain of personal helpers through clothing redesign. Applied Ergonomics, 34, 557-563.

Park, J. Morris, K., Stannard, C. \& Hamilton, W. (2014). Design for Many, Design for Me:

Universal Design for Apparel Products. The Design Journal, 17(2), 267-290.

Story, M.F., Mueller, J.L. \& Mace, R.L. (1998). The universal design file: Designing for people of all ages. Raleigh NC: North Carolina State University.

Yamazaki, K., Oya, R., Nagahama, K., Okada, K., \& Inaba, M. (2016). Bottom dressing by a dual-arm robot using a clothing state estimation based on dynamic shape changes. International Journal of Advanced Robotic Systems, 13(1), 5.

Textile World Record. An Improved Undershirt, October 1914 - March 1915, pp. 145-146

USPTO. (2018). History of changes to patent terms. Accessed June 10, 2020. Available online at: https://www.uspto.gov/patent/laws-and-regulations/patent-term-calculator

Page 3 of 3

(c) 2020 The author(s). Published under a Creative Commons Attribution License (https://creativecommons.org/licenses/by/4.0/), which permits unrestricted use, distribution, and reproduction in any medium, provided the original work is properly cited.

ITAA Proceedings, \#77 - https://itaaonline.org 